\title{
A prospective observational study of thyroid dysfunctions during pregnancy in a tertiary care hospital
}

\section{Sarojamma Chunchaiah ${ }^{1 *}$, Nagendra Prasad ${ }^{2}$, Murali B. M. ${ }^{3}$, Rupakala B. M. ${ }^{4}$, Nagarathnamma Rangaiah ${ }^{5}$}

\author{
1,2,4,5 Department of Obstetrics and Gynecology, Rajarajeswari Medical College and Hospital, Bangalore, India \\ ${ }^{3}$ Consultant Pathologist, Bangalore, India
}

Received: 04 October 2016

Accepted: 10 October 2016

\author{
*Correspondence: \\ Dr. Sarojamma Chunchaiah, \\ E-mail: drsarojamurali@yahoo.com
}

Copyright: (c) the author(s), publisher and licensee Medip Academy. This is an open-access article distributed under the terms of the Creative Commons Attribution Non-Commercial License, which permits unrestricted non-commercial use, distribution, and reproduction in any medium, provided the original work is properly cited.

\section{ABSTRACT}

Background: Thyroid dysfunctions are the second most common endocrine disorders seen during pregnancy. Overt or subclinical thyroid dysfunction during pregnancy adversely affects maternal and fetal outcomes. Maternal euthyroid status in early gestation period and optimal transfer of thyroxine to fetus is crucial for the optimal growth, development and maturation of fetal nervous system. This study is undertaken to know the magnitude of thyroid dysfunctions during pregnancy in our region and to validate the need for early detection of maternal thyroid dysfunctions by antenatal screening.

Methods: It was a hospital based prospective study over a period of one year. According to our study criteria, blood samples were collected from consenting pregnant woman during their first antenatal visit and analyzed for TSH level by ultrasensitive method. Free T3 and Free T4 were assayed in patients showing abnormal TSH level and anti thyroid peroxide antibodies tested in all hypothyroid patients. All pregnant woman enrolled were followed up throughout the pregnancy, labour and postpartum to note any maternal and fetal adverse outcomes. The data obtained were analyzed and pregnancy outcomes compared between women showing thyroid dysfunctions and euthyroid state.

Results: Among 800 pregnant women studied $88.75 \%$ were euthyroid and $11.25 \%$ showed thyroid dysfunction, affecting more in the age group 21-25 years and multigravidae. Prevalence of hypothyroidism was $10.12 \%$, presenting as subclinical hypothyroidism $(7.37 \%)$ and overt hypothyroidism $(2.75 \%)$. Hyperthyroidism was seen in $1.12 \%$ of cases, $0.87 \%$ of them presented subclinically and $0.25 \%$ overtly. Risk factor was present in $29.62 \%$ of hypothyroid group and $33.33 \%$ of hyperthyroid group. Pregnancy complications were seen in $55.55 \%$ of thyroid dysfunctional group, preeclampsia being the most common complication.

Conclusions: Our study showed $11.25 \%$ prevalence of thyroid dysfunction in pregnant women and commonest dysfunction was hypothyroidism in subclinical form. Adverse pregnancy outcomes were seen in 55.55\% woman having thyroid dysfunctions. Absence of risk factor was noted in upto $70 \%$ of the cases with thyroid dysfunctions hence the diagnosis will be missed if only high risk cases are screened. Therefore universal screening is recommended early in pregnancy to identify and correct thyroid dysfunctions to prevent the associated adverse pregnancy outcomes.

Keywords: Adverse pregnancy outcomes, Hypothyroidism, Thyroid dysfunction, Subclinical hypothyroidism, Hyperthyroidism

\section{INTRODUCTION}

Thyroid disorders constitute the second most common endocrinal dysfunctions during pregnancy. ${ }^{1}$ Thyroid dysfunction during pregnancy has a relatively high prevalence of about $2-5 \%$. $^{2}$ Maternal hypothyroidism
$(10.1 \%)$ is the most common thyroid dysfunction seen during pregnancy presenting more in subclinical form $(9.3 \%)$ than overt $(0.72 \%) .^{3}$ The prevalence of hyperthyroidism during pregnancy is less common $(0.6 \%)$ than hypothyroidism. ${ }^{4} 10-20 \%$ of euthyroid pregnant women are positive for anti TPO antibodies or 
anti-thyroglobulin antibodies in the first trimester significant number of them will develop hypothyroidism (TSH $>3 \mathrm{mIU} / \mathrm{l})$ in third trimester and Postpartum thyroiditis. 5

Thyroid hormone production increases by $50 \%$ in maternal thyroid gland due to the physiological changes of pregnancy. Marked increase in estrogen concentration increases synthesis of thyroxine binding globulin (TBG) from liver, resulting in increased binding of $\mathrm{T} 4$. The distribution of $\mathrm{T} 4$ is higher during pregnancy due to increase in maternal plasma volume. A significant amount of thyroxine is transferred through placenta and placental de-iodinases converts T4 to T3. These changes can increase the total T3 and T4 levels by 30 to $40 \%$ and this alters the equilibrium between the bound and free thyroid hormone levels causing decrease in Free T4 and increase in TSH level. Eighty five percent structural similarity between Beta-HCG and alpha subunit of TSH results in direct thyrotropic activity leading to decrease in TSH levels during early pregnancy as compared to nonpregnant women. ${ }^{6,7}$

During first trimester of pregnancy the developing fetus depends exclusively on maternal thyroid hormone supply for brain development, neuronal growth and lung maturation, but second trimester onwards the thyroxine demand is met by both mother and fetus. Alteration in thyroid function of mother can adversely affect fetus due to transfer of abnormal level of thyroid hormones, anti thyroid antibodies and medications across the placenta. During early gestation, if mother is hypothyroid and Iodine deficient, the baby can have long lasting neuropsychological consequences, reduced IQ and visual motor defects due to inadequate transfer of maternal thyroid hormones across placenta to the developing fetus. $^{8,9}$ Isolated hypothyroxinemia (Low FT4 level and Normal TSH level) secondary to Iodine deficiency or autoimmune thyroid disease result in lower IQ in infants and children and not associated with other adverse perinatal outcomes. $^{10}$

The most common cause of both hypo and hyperthyroidism is autoimmune thyroiditis, Hashimoto's thyroiditis being the most common cause for hypothyroidism. Overt hypothyroidism is seen in 5\% of women with high TSH levels and subclinical hypothyroidism $(\mathrm{SCH})$ show no clinical symptoms but over half of them show evidence of auto immune thyroid disease by having anti thyroid peroxidase antibodies (anti TPO $\mathrm{ab}$ ) and/or anti thyroglobulin antibodies. Iodine deficiency is the common cause of hypothyroidism during pregnancy in endemic Iodine deficient areas. Iodine is an important substrate for thyroxine synthesis and during pregnancy there is increased demand for Iodine but the increased renal clearance of Iodine leads to its reduced bioavailability. ${ }^{11,12}$ Ten percent euthyroid pregnant women show anti thyroid peroxidase antibodies at 14 weeks of gestation and some of them will present as $\mathrm{SCH}$, over half of them will develop postpartum thyroiditis. ${ }^{13}$ Graves' disease accounts for more than $85 \%$ cases of hyperthyroidism, characterized by positive TSH receptor binding antibody (TSHRAb) which decreases in titre throughout gestation. Measurement of TSHRAb is not warranted in subclinical hyperthyroidism because of low incidence of the condition, although the establishment of cause and treatment of subclinical hyperthyroidism improves the pregnancy outcome. ${ }^{14,15}$

Diagnosing thyroid dysfunction during pregnancy is not easy due to the impact of thyroid homeostasis which makes interpretation of thyroid function difficult. Symptoms of hypothyroidism can be masked by the hyperdynamic state of pregnancy. Clinical features of hyperthyroidism may not be very obvious during pregnancy as tachycardia, sweating, dyspnoea and nervousness are also seen in normal pregnancy. If non pregnant TSH reference values are used in the diagnosis of thyroid disorders during pregnancy, $3.6 \%$ of patients with elevated TSH would be missed. ${ }^{16} \mathrm{~A} 3.7 \%$ increase of prevalence of hypothyroxemia is noted when the first trimester specific reference ranges were used instead of general population reference values. ${ }^{17}$ To overcome the difficulties in diagnosis a trimester specific reference ranges and assay specific TSH estimation is used.

Maternal hypothyroidism, overt or subclinical during pregnancy can adversely affect pregnancy outcomes like preeclampsia (PE), gestational diabetes mellitus(GDM), maternal anemia, preterm labour, abruptio placenta, postpartum hemorrhage, postpartum thyroiditis, miscarriage, prematurity, low birth weight (LBW), intrauterine growth restriction (IUGR), increased neonatal respiratory distress, and intrauterine death (IUD). ${ }^{18,19}$ Significant adverse pregnancy outcomes are associated with overt hyperthyroidism but not with subclinical hyperthyroidism. ${ }^{20}$ Early detection and appropriate treatment of thyroid dysfunctions during pregnancy can prevent or ameliorate many of the adverse maternal and fetal outcomes.

The aims of this study are:

- To estimate and evaluate the prevalence and pattern of thyroid dysfunctions during pregnancy

- To study the maternal and fetal outcome in pregnancies with thyroid dysfunctions

- To validate the need for early detection of maternal thyroid dysfunctions by antenatal screening

\section{METHODS}

This is an observational prospective study done at RRMCH, $\mathrm{Ob}$ and $\mathrm{G}$ department over a period of 12 months between January 2015 and December 2015. A total of 800 pregnant women were enrolled for the study after obtaining the informed consent. 


\section{Inclusion criteria}

- Pregnant women of varying gestational period in their first antenatal visit.

- Pregnant women with thyroid problems, with or without medication.

\section{Exclusion criteria}

- Pregnant women who were on drugs like iodine, lithium, amidarone etc.

- Pregnant women with other medical conditions like Diabetes mellitus, collagen diseases and heart diseases

- Pregnant women with multiple pregnancy, molar pregnancy and ectopic pregnancy.

Detailed history was taken and examination was done as per proforma. History was used to assess the risk factors for thyroid dysfunctions regarding age $>30$, morbid obesity $(\mathrm{BMI}>40)$, residing in severe iodine efficient area, signs and symptoms suggestive of thyroid disorder, past history of thyroid disorder, infertility, miscarriage, therapeutic radiation to head and neck, use of lithium, amidarone, recent administration of iodinated radiologic contrast media, family history of thyroid disorder, presence of thyroid swelling, presence of thyroid antibodies, autoimmunity and history of type 1 diabetes mellitus.

Serum samples were collected and TSH estimation was done by using ultrasensitive sandwich chemiluminescent method. When TSH was abnormal free T3 and free T4 were estimated by competitive chemiluminescent immunoassay. Anti TPO ab estimation was done in hypothyroid cases by using fully automated chemiluminescent immunoassay. Measurement of TSH receptor antibody was not done in our study.

Because of the wide variation of reference ranges used in different studies trimester and method specific TSH, free T4 and Free T3 values as per ATA 2011 are taken as reference values in our study.

\section{TSH reference range:}

- First trimester : 0.1-2.5 mIU/L

- Second trimester : 0.2-3.0 mIU/L

- Third trimester : 0.3-3.0 mIU/L are considered normal

\section{Free $T 4$ reference range:}

- $\quad$ First trimester: $1.3+0.23 \mathrm{pmol} / \mathrm{L}$

- Second trimester: $0.22+0.30 \mathrm{pmol} / \mathrm{L}$

- Third trimester: $0.86+0.21 \mathrm{pmol} / \mathrm{L}$

Anti-TPO ab reference range: $<35 \mathrm{IU}$
Overt hypothyroidism $(\mathrm{OH})$ is diagnosed with increase in serum TSH of $>10.0$ or TSH between $2.5-10$ with low free T3 and free T4 levels. Subclinical hypothyroidism is diagnosed with TSH of $>2.5$ in first trimester and $>3.0$ second and third trimester with normal Free T3 and free T4 levels. Measurement of Anti TPO Ab was done in all hypothyroid patients and a value of $>35$ were taken as abnormal. Overt hyperthyroidism is diagnosed whenever there is high free T3 and T4 levels with low TSH values less than 0.1. Subclinical hyperthyroidism was diagnosed when TSH values were low with normal Free T3 and T4 values. Isolated hypothyroxinemia is diagnosed when normal maternal TSH level with free T4 levels in the lower $5^{\text {th }}$ or $10^{\text {th }}$ percentile of reference range is seen.

Women diagnosed with abnormal thyroid functions were referred to endocrinology department for treatment. Hypothyroid patients (both $\mathrm{SCH}$ and $\mathrm{OH}$ ) were treated with levothyroxine and iodine deficiency was corrected. Hyperthyroidism patients were treated with propylthiouracil. Repeat blood tests were done at 4-6 weeks intervals and dosages of medications were adjusted to keep the serum TSH levels within normal limits. All the pregnant women enrolled were followed up throughout pregnancy, labour and postpartum period to note any adverse maternal and fetal outcomes. Results were analyzed by chi square test using Open Epi. pregnancy outcomes compared between thyroid dysfunction and euthyroid group.

\section{RESULTS}

Table 1: Demographic profile of pregnant women with thyroid dysfunctions.

\begin{tabular}{|ll|}
\hline Variables & Number and percentage \\
\hline Age & \\
\hline$<20$ & $9(10 \%)$ \\
\hline $21-25$ & $38(42.22 \%)$ \\
\hline $26-30$ & $32(35.55 \%)$ \\
\hline $31-35$ & $6(6.66 \%)$ \\
\hline$>35$ & $5(5.55 \%)$ \\
\hline Gravida of women & \\
\hline Primigravida & $41(45.55 \%)$ \\
\hline Multigravida & $49(54.44 \%)$ \\
\hline Trimester & \\
$1^{\text {st }}$ & $55(61.11 \%)$ \\
$2^{\text {nd }}$ & $20(22.22 \%)$ \\
$3^{\text {rd }}$ & $15(16.67 \%)$ \\
\hline BMI $\left(\mathrm{kg} / \mathrm{m}^{2}\right)$ & \\
\hline$<30$ & $65(72.22 \%)$ \\
\hline$>30$ & $25(27.77 \%)$ \\
\hline$>40($ Morbid $)$ & 0 \\
\hline
\end{tabular}

In our study of 800 antenatal women screened for thyroid disorders, 90 showed thyroid dysfunctions. A prevalence of $11.25 \%$ thyroid dysfunction was seen with highest number of cases belongs to age group of 21-25 years. Thyroid dysfunctions was more in multigravida $(54.44 \%)$ 
than primigravida $(45.55 \%)$, more commonly seen in first trimester $(66.11 \%)$ than second trimester $(22.22 \%)$ and third trimester $(16.67 \%)$. Obesity with BMI more than 30 was seen in $27.77 \%$ and there was no case of morbid obesity (Table 1).

The commonest dysfunction seen was hypothyroidism in subclinical form $7.37 \%$. The prevalence and pattern of other thyroid dysfunctions are shown in Table 2.

The newly detected cases of thyroid disorders were more than old cases (Table 3 ).

Anti-TPO Ab was positive in 10 out of $59(16.94 \%)$ subclinical hypothyroid cases and 6 out of $22(27.27 \%)$ in overt hypothyroid cases (Table 4).

Presence of high risk factors was seen in $30 \%$ of women with thyroid dysfunctions. No risk factor was seen in $70 \%$ of cases (Table 5).

Table 2: Prevalence and pattern of thyroid dysfunctions seen during pregnancy.

\begin{tabular}{|cll|}
\hline & Number & Percentage (\%) \\
\hline Hypothyroid & $81 / 800$ & 10.125 \\
\hline$\bullet \quad$ SCH & $59 / 800$ & 7.37 \\
\hline$\bullet$ Overt & $22 / 800$ & 2.75 \\
\hline Hyperthyroidism & $9 / 800$ & 1.125 \\
\hline$\bullet \quad$ Subclinical & $7 / 800$ & 0.87 \\
\hline$\bullet \quad$ Overt & $2 / 800$ & 0.25 \\
\hline $\begin{array}{l}\text { Isolated } \\
\text { Hypothyroxinemia }\end{array}$ & $0 / 800$ & 0 \\
\hline Euthyroid & $710 / 800$ & 88.75 \\
\hline
\end{tabular}

Table 3: Distribution of thyroid dysfunctions seen during pregnancy.

\begin{tabular}{|c|c|c|}
\hline & Number & Percentage $(\%)$ \\
\hline \multicolumn{3}{|l|}{ Hypothyroid } \\
\hline - Old case & 30 & 37.03 \\
\hline - Newly detected & 51 & 62.96 \\
\hline \multicolumn{3}{|l|}{ Hyperthyroid } \\
\hline - Old cases & 4 & 44.44 \\
\hline - Newly detected & 5 & 55.55 \\
\hline
\end{tabular}

Table 4: Number of Anti-TPO Ab positivity among hypothyroid patients.

\begin{tabular}{|lll|}
\hline & Number & Percentage (\%) \\
\hline $\begin{array}{l}\text { Subclinical } \\
\text { hypothyroidism }(\mathrm{n}=59)\end{array}$ & 10 & 16.74 \\
\hline $\begin{array}{l}\text { Overt hypothyroidism } \\
(\mathrm{n}=22)\end{array}$ & 6 & 27.27 \\
\hline
\end{tabular}

Table 5: Number of cases associated with risk factors for thyroid disorders.

\begin{tabular}{|c|c|c|c|c|}
\hline \multirow{2}{*}{$\begin{array}{l}\text { Thyroid } \\
\text { disorders }\end{array}$} & \multicolumn{2}{|c|}{$\begin{array}{l}\text { Risk factor } \\
\text { identified }\end{array}$} & \multirow{2}{*}{ Total } & \multirow{2}{*}{$\begin{array}{l}\text { Percentage } \\
(\%)\end{array}$} \\
\hline & $\begin{array}{l}\text { Antibody } \\
\text { positivity }\end{array}$ & $\begin{array}{l}\text { Age } \\
>\mathbf{3 0 y}\end{array}$ & & \\
\hline Hypothyroidism & $16 / 81$ & $8 / 81$ & $24 / 81$ & 29.62 \\
\hline Hyperthyroidism & Not done & $3 / 9$ & $3 / 9$ & 33.33 \\
\hline
\end{tabular}

Pregnancy complications are seen in $55.55 \%$ of thyroid dysfunctional group. Most common complication seen was preeclampsia (Table 6).

Table 6: Pregnancy complications seen in women with thyroid dysfunction.

\begin{tabular}{|llllll|}
\hline Complications & Euthyroid & Overt hypothyroidism & SCH & Hyperthyroidism & p value \\
\hline Abortion & $44(6.19 \%)$ & $2(9.09 \%)$ & $7(11.86 \%)$ & $1(11.11 \%)$ & 0.080 \\
\hline PE & $38(5.35 \%)$ & $3(13.63 \%)$ & $8(13.55 \%)$ & $2(22.22 \%)$ & $0.001 *$ \\
\hline GDM & $19(2.67 \%)$ & $2(9.09 \%)$ & $5(8.47 \%)$ & $1(11.11 \%)$ & $0.002 *$ \\
\hline Maternal Anaemia & $30(4.22 \%)$ & $2(9.09 \%)$ & $5(8.47 \%)$ & - & 0.130 \\
\hline Preterm Labour & $25(3.52 \%)$ & $2(9.09 \%)$ & $3(5.08 \%)$ & $1(11.11 \%)$ & 0.145 \\
\hline IUGR & $34(4.78 \%)$ & $2(9.09 \%)$ & $2(3.38 \%)$ & 0 & NA \\
\hline Still Birth & $7(0.98 \%)$ & $1(4.54 \%)$ & $1(1.69 \%)$ & 0 & NA \\
\hline Complication Rate & $197 / 710(27.74 \%)$ & $14 / 22(63.63 \%)$ & $31 / 59(52.54 \%)$ & $5 / 9(55.55 \%)$ & - \\
\hline
\end{tabular}

*Statistically significant; NA - Not Assessed

\section{DISCUSSION}

Our study showed a prevalence of $11.25 \%$ of thyroid dysfunction during pregnancy, affecting more in first trimester, multigravidae belonging to age group of 21-25 years which is comparable to demographic profile of Shaw MJ et al and prevalence $(12 \%)$ in the study by
Thammaih $\mathbf{J}$ et al. There were 11 cases in the age group of more than 30 years which is a high risk factor. Multigravidas with previous miscarriages are more than primigravidae may be due to undiagnosed thyroid dysfunctions. More cases detected in first trimester because screening was done in the first visit of the pregnant women. Out of 90 cases with thyroid 
dysfunction, 56 were newly detected and 34 were already diagnosed cases.

Prevalence of hypothyroidism was $10.12 \%$ in our study which is comparable to study by Sahasrabuddhe A et al, of which overt hypothyroidism cases were $2.75 \%$ and subclinical hypothyroidism cases were $7.37 \%$ which are comparable to study by Pavanganga A et al (overt $0.72 \%$ and $\mathrm{SCH} 9.3 \%$ ) and Jitesh M Shaw et.al (overt $0.9 \%$ and $3.5 \%$ of $\mathrm{SCH}$ ). Subclinical hypothyroidism is more prevalent and often undiagnosed unless specific screening test is used. Anti TPO ab were positive in $16.94 \%$ of $\mathrm{SCH}$ group and $27.27 \%$ of $\mathrm{OH}$ group in our study which are comparable to $17.9 \%$ and $33.3 \%$ respectively in Pavanaganga A, et al study. ${ }^{1,3,4}$ Gestational hyperthyroidism is uncommon and our study showed a prevalence of $1.2 \%$ (overt $0.25 \%$ and $\mathrm{SCH} 0.87 \%$ ) similar to studies by Jithesh M Shaw et al showing $1.4 \%$ (overt $0.6 \%$ and $\mathrm{SCH} 0.8 \%$ ) and Casey BM et al showed that subclinical hyperthyroidism in $1.7 \%$ of pregnant women. ${ }^{4,20}$

There are no guidelines upon screening strategy for thyroid dysfunctions in India during pregnancy and there is no consensus upon universal screening versus screening of high risk women. We used universal screening strategy in our study which showed risk factors in $29.62 \%$ of hypothyroid and $33.33 \%$ of hyperthyroid cases and upto $70 \%$ of thyroid dysfunction cases did not have any risk factors. Study by Horacek et al point out that over half of pregnant women with thyroid abnormality suggestive of autoimmune thyroiditis or hypothyroidism would be missed if only high risk cases are screened. A study by Wang W et al concluded that case finding strategy for screening wound miss about $81.6 \%$ of pregnant women with hypothyroidism and $80.4 \%$ of woman with hyperthyroidism. Routine screening for thyroid disorders by serum TSH before or during first trimester of pregnancy was recommended by the American Association of clinical endocrinology in 2002. ${ }^{22,23}$ Currently ATA and ACOG do not recommend routine screening of asymptomatic woman and recommend screening for patients having high risk factor for thyroid disorder. ${ }^{5,24}$

The available evidences relating low IQ in children to maternal hypothyroidism suggests the need for thyroid function screening early in pregnancy and treatment with L-thyroxine in appropriate women would be beneficial. Comparative studies show cost effectiveness of routine screening over no screening in SCH during pregnancy. ${ }^{25,26}$ In contrast to above studies CATS study which compared outcome of levothyroxine therapy in women with the hyopothyroidism in pregnancy screened prior to 16 weeks of gestation and treated compared with controls who were not screened and not treated did not show any benefit in child IQ at 3 years of age. ${ }^{27}$ Because of low incidence of hyperthyroidism in pregnancy, universal screening for hyperthyroidism does not seem to be cost effective. ${ }^{5}$
Review article by Lazarus $\mathrm{JH}$ concluded that $\mathrm{SCH}$ in pregnancy fulfils the criteria for screening as the condition is common and medically important having a simple screening test and effective available treatment. ${ }^{28}$ The prevalence of $\mathrm{SCH}$ is increasing during pregnancy like undetected bottom of an iceberg and is associated with adverse pregnancy outcomes. Hence early detection of $\mathrm{SCH}$ by screening and appropriate treatment with levothyroxine can prevent maternal and fetal complications. ${ }^{3}$

Many studies have shown association of adverse pregnancy outcomes in cases of pregnancy with thyroid dysfunction. In our study Table 6, shows pregnancy complications seen in the thyroid dysfunctional group. Pregnant woman with overt hypothyroidism had adverse effects $2(9.09 \%)$ miscarriage, 3 (13.63\%) PE, 2 (9.09\%) GDM, $2(9.09 \%)$ maternal anemia, $2(9.09 \%)$ preterm labour, 1 (4.54\%) still birth and 2 (9.09\%) IUGR. Various studies have shown a strong association between $\mathrm{OH}$ and adverse fetomaternal outcome. Allen et.al noted increased risk of fetal death among pregnant woman with $\mathrm{OH}$. Sahu et al showed $60 \%$ risk of fetal loss when $\mathrm{OH}$ was not adequately treated during pregnancy. Leung et al showed a $22 \%$ increased risk of developing gestational hypertension in pregnant women with $\mathrm{OH}$ when compared to SCH or Euthyroid group. ${ }^{18,19,29}$

We observed pregnancy complications in cases of $\mathrm{SCH}$ as given in Table 6 . Though there are conflicting reports about effects of $\mathrm{SCH}$ on maternal and fetal outcome, majority of high quality evidence suggests that $\mathrm{SCH}$ is associated with increased risk of adverse pregnancy outcome. Study by Negro et al suggests that $\mathrm{SCH}$ increases the risk of pregnancy complications in anti TPO ab positive women. Study of Ashoor et al showed that pregnancies which resulted in miscarriages had TSH values above the 97.5 percentile. ${ }^{30,31}$ Study by Wilson, Karen, Casey et al showed that subclinical thyroid disease is associated with increased incidence of hypertension in pregnancy. Thyroid hormones exert an effect over cardiovascular physiology and blood pressure regulation through genomic mechanism that causes ventricular remodelling. Studies have proven that hypothyroidism causes endothelial dysfunction characterized by diminished nitric oxide production which in turn leads impaired vascular relaxation and resulting in development of hypertension. ${ }^{32}$

Maternal anemia was noted in $7.77 \%$ of thyroid dysfunctional group in our study. Thyroid hormones increase hematopoiesis by increasing erythropoietin production in renal cells, hypothyroidism causes decrease in red cell mass and hypoproliferation of euthyroid progenitors. It also affects iron absorption by decreasing acid secretion in stomach there by impairing iron absorption and causing anemia. ${ }^{33,34}$

Ours study showed $8.88 \%$ GDM in thyroid dysfunctional group which is comparable to study by Karkosta et al 
Increased incidence of GDM in patients with hypothyroidism is due to decreased rate of insulin stimulated glucose transport and increased insulin resistence. $^{35,36}$

Table 6 shows adverse effects of hyperthyroidism on maternal and fetal outcome in our study. Studies have shown that adverse pregnancy outcomes are directly related to duration of euthyroid state and control of hyperthyroidism during pregnancy. Thyrotoxicosis when poorly controlled is associated with miscarriage, $\mathrm{PIH}$, prematurity, thyroid storm and congestive heart failure. $^{14,20}$

Pregnancy complications seen in thyroid dysfunction group in our study was comparable to study by Shaw M Jitesh. $^{4}$ Many complications are not statistically significant except for preeclampsia and GDM which may be due to majority of cases were detected early, treated and maintained in euthyroid state throughout pregnancy, labour and post partum. LSCS and assisted delivery rates were higher in our study population as compared to euthyroid patients, maybe due to associated obstetric complications.

Limitations of our study are no comparison of outcome between early versus late detected cases, treated and untreated cases and antibody positive and antibody negative cases.

\section{CONCLUSION}

Prevalence of thyroid dysfunction was $11.25 \%$ in our study. The commonest dysfunction noted was maternal hypothyroidism $(10.12 \%)$ which presented as $\mathrm{SCH}$ in $7.37 \%$ and $\mathrm{OH}$ in $2.75 \%$ of cases. Low prevalence of hyperthyroidism $(1.12 \%)$ was noted which presented subclinically in $0.87 \%$ and overtly in $0.25 \%$ of cases Overall pregnancy complication rate in affected women was $55.55 \%$ and statistically significant complications noted are preeclampsia and GDM. The diagnosis of thyroid dysfunctions during pregnancy is difficult and upto $70 \%$ of thyroid dysfunctional cases will be missed if only high risk cases are screened. Therefore universal screening for thyroid dysfunction should be considered in view of high prevalence of disease and associated complications during pregnancy.

Screening should be done by estimation of serum TSH levels, as it is the most sensitive indicator of thyroid function. It should be done ideally in the first trimester of pregnancy to detect the dysfunctions early, to treat and prevent complications.

\section{ACKNOWLEDGEMENTS}

We sincerely thank Mr. Anmol M, Master. Anikethan M and Dr. Rishikesh for typing manuscript, preparing charts and statistical assistance. We are grateful to Chairman, Medical director and Principal of Rajarajeswari Medical
College and Hospital for their support and encouragement.

Funding: No funding sources

Conflict of interest: None declared

Ethical approval: The study was approved by the Institutional Ethics Committee

\section{REFERENCES}

1. Sahasrabuddhe A, Pitale S. Screening for thyroid dysfunction during pregnancy. Thyroid Res Pract. 2012;9:15-7.

2. Unnikrishnan AG, Kalra S. Prevalence of hypothyroidism in adults: an epidemiological study in eight cities of India: Indian J of endocrinology and metabolism. 2013;32(192):397-403.

3. Pavanaganga A. Observational Study of Subclinical Hypothyroidism in Pregnancy: Indian Journal of Obstetrics and Gynaecology Research. 2015;2(4):255-60.

4. Shah JM, Mehta MN, Viradia HB. Screening for thyroid dysfunction during pregnancy. Thyroid Res Pract. 2013;10:65-7.

5. Stagnaro-Green A, Abalovich M, Alexander E. Guidelines of the American Thyroid Association for the diagnosis and management of thyroid disease during pregnancy and postpartum. Thyroid. 2011;21(10)

6. Lindberg BS, Johansson ED, Nilsson BA. Plasma levels of nonconjugated oestrone, oestradiol-17beta and oestriol during uncomplicated pregnancy: Acta Obstet Gynecol Scand Suppl. 1974;32(0):21-36.

7. Robbins J, Nelson JH. Thyroxine binding by serum protein in pregnancy and in the newborn: $\mathrm{J}$ Clin Invest. 1958 Feb;37(2):153-9.

8. Haddow JE, Palomaki GE, Allan WC, Williams JR, Knight GJ, Gagnon J. Maternal thyroid deficiency during pregnancy and subsequent neuropsychological development of the child. N Engl J Med. 1999;341:549-55.

9. Zoeller RT, Rovet J. Timing of thyroid hormone action in the developing brain: Clinical observations and experimental findings. J Neuroendocrinol. 2004; 16:809-18.

10. Casey BM, Dashe JS, Spong CY, McIntire DD, Leveno KJ, Cunningham GF. Perinatal significance of isolated maternal hypothyroxinemia identified in the first half of pregnancy, Obstetrics and Gynecology. 2007;109,5:1129-35.

11. Negro R. Thyroid insufficiency during pregnancy: complications and implications for screening. Expert Review of Endocrinology and Metabolism. 2008;3,2:137-46.

12. Joanna K, Burman KD. Levothyroxine Treatment in Pregnancy: indications, efficacy and therapeutic regimen. J of Thyroid Research, 2011. Article ID 843591.

13. Roti E, Uberti E. Post-partum thyroiditis- a clinical update. Eur J Endocrinol. 2002;146:275-9. 
14. Patil-Sisodia K, Mestman JH. Graves hyperthyroidism and pregnancy: a clinical update, Endocrine Practice. 2010;16,1:118-29.

15. Lazarus JH, Kaklamanou M. Significance of low thyroid-stimulating hormone in pregnancy, Current Opinion in Endocrinology, Diabetes and Obesity. 2007;14,5:389-92.

16. Stricker RT, Echenard M, Eberhart R. Evaluation of maternal thyroid function during pregnancy: the importance of using gestational age-specific reference intervals. European Journal of Endocrinology. 2007;157:509-14.

17. Vaidya B, Anthony S, Bilous M, Shields B, Drury J, Hutchison S, et al. Detection of thyroid dysfunction in early pregnancy: universal screening or targeted high-risk case finding. Journal of Clinical Endocrinology and Metabolism. 2007;92:203-7.

18. Allan WC, Haddow JE, Palomaki GE, Williams JR, Mitchell ML, Hermos RJ, et al. Maternal thyroid deficiency and pregnancy complications: implications for population screening. J Med Screen. 2000;7:127-30.

19. Sahu MT, Das V, Mittal S. Overt and subclinical thyroid dysfunction among Indian pregnant women and its effect on maternal and fetal outcome: Archieves of gynaecology and obstetrics. 2010 Feb;281(2):215-20.

20. Casey BM, Dashe JS, Wells CE, McIntire DD, Leveno KJ, Cunningham FG. Subclinical hyperthyroidism and pregnancy outcomes, Obstetrics and Gynecology. 2006;107,2:337-41.

21. Thammiah J. Screening for thyroid disorders in pregnancy with TSH estimation. Int $\mathrm{J}$ Reprod Contracept Obstet Gynecol. 2016;5:1052-5.

22. Horacek J, Spitalnikova S, Dlabalova B, Malirova E, Vizda J, Svilias I. Universal screening detects twotimes more thyroid disorders in early pregnancy than targeted high-risk case finding. Eur J Endocrinol. 2010;163;645-50.

23. Wang W. The prevalence of thyroid disorders during early pregnancy in China: the benefits of universal screening in the first trimester of pregnancy. European Journal of Endocrinology. 2011 Feb;164(2):263-8.

24. American College of Obstetricians and Gynecologists. ACOG Practice Bulletin. Clinical management guidelines for obstetriciangynecologists. Number 37, August 2002. (Replaces Practice Bulletin Number 32, November 2001). Thyroid disease in pregnancy. Obstet Gynecol 2002;100:387-96.

25. Thung SF, Funai EF, Grobman WA. The cost effectiveness of universal screening in pregnancy for subclinical hypothyroidism, American Journal of Obstetrics and Gynecology. 2009;200(3):267-e1.

26. Dosiou C, Sanders GD, Araki SS, Crapo LM. Screening pregnant women for autoimmune thyroid disease: a cost-effectiveness analysis, European Journal of Endocrinology. 2008;158(6):841-51.

27. Lazarus J. Outcome of the controlled antenatal thyroid screening study. Endocrine Abstracts. 2012;29:S52.1.

28. Lazarus JH. Screening for thyroid dysfunction in pregnancy: Is it worthwhile? J Thyroid Res 2011:397012.

29. Leung AS, Millar LK, Koonings PP, Montoro M, Mestman JH. Perinatal outcome in hypothyroid pregnancies. Obstet Gynecol. 1993;81:349-53.

30. Negro R, Schwartz A, Gismondi R, Tinelli A, Mangieri T, Stagnaro-Green A. Universal screening versus case finding for detection and treatment of thyroid hormonal dysfunction during pregnancy. J Clin Endocrinol Metab. 2010;95:1699-1707.

31. Ashoor G, Maiz N, Rotas M, Jawdat F, Nicolaides $\mathrm{KH}$. Maternal thyroid function at 11 to 13 weeks of gestation and subsequent fetal death. Thyroid. 2010;20:989-93.

32. Wilson, Karen, Casey. Subclinical thyroid disease and the incidence of hypertension in pregnancy. Obstetrics Gynecology Journal. 2012;119:315-20.

33. Rana R, Joshi K. Screening of pregnant women for Iodine deficiency and Iron deficiency during early gestation in Vadodara.

34. Ravanbond M, Kamya. Treatment of iron deficiency anaemia in patients with subclinical hypothyroidism. The American journal of Medicine. 2014;126(5):420-4.

35. Karakosta P, Alegakis D. Thyroid dysfunction and autoantibodies in early pregnancy are associated with increased risk of gestational diabetes and adverse birth outcomes: J clinical endocrinology metabolism. 2012 Dec; 97(12):4464-72.

36. Lambadiari V, Mitrou P, Maratou E, Raptis AE, Tountas N, Raptis, SA, et al. Thyroid hormones are positively associated with insulin resistance early in the development of type 2 diabetes: Endocrine. 2011;39:28-32.

Cite this article as: Chunchaiah S, Prasad N, Murali BM, Rupakala BM, Rangaiah N. A prospective observational study of thyroid dysfunctions during pregnancy in a tertiary care hospital. Int J Reprod Contracept Obstet Gynecol 2016;5:3683-9. 